\title{
Mass Spectrometry and Multiplex Antigen Assays to Assess Microbial Quality and Toxin Production of Staphylococcus aureus Strains Isolated from Clinical and Food Samples
}

\author{
Paul Attien, ${ }^{1,2,3}$ Haziz Sina, ${ }^{2}$ Wardi Moussaoui, ${ }^{4}$ Gaëlle Zimmermann-Meisse, ${ }^{4}$ \\ Thomas Dadié, ${ }^{1}$ Daniel Keller, ${ }^{4}$ Philippe Riegel, ${ }^{4}$ Vincent Edoh, ${ }^{3}$ Simeon O. Kotchoni, ${ }^{5}$ \\ Marcellin Djè, ${ }^{1}$ Gilles Prévost, ${ }^{4}$ and Lamine Baba-Moussa ${ }^{2}$ \\ ${ }^{1}$ Laboratoire de Biotechnologie et Microbiologie des Aliments, Faculté des Sciences et Technologies des Aliments, \\ Université Nangui Abroguoua, BP 801 Abidjan 02, Cote D’Ivoire \\ ${ }^{2}$ Laboratoire de Biologie et de Typage Moléculaire en Microbiologie, Faculté des Sciences et Techniques, \\ Université d'Abomey-Calavi, 05 BP 1604 Cotonou, Benin \\ ${ }^{3}$ Laboratoire de Bactériologie et Virologie, Faculté des Sciences Médicales, Centre Hospitalier et Universitaire de Treichville, \\ BP V3 Abidjan, Cote D'Ivoire \\ ${ }^{4}$ Université de Strasbourg (CHRU Strasbourg), Fédération de Médecine Translationnelle de Strasbourg, \\ EA 7290 Virulence Bactérienne Précoce, Institut de Bactériologie, 3 rue Koeberlé, 67000 Strasbourg, France \\ ${ }^{5}$ Department of Biology and Center for Computational and Integrative Biology, Rutgers University, 315 Penn Street, \\ Camden, NJ 08102, USA
}

Correspondence should be addressed to Lamine Baba-Moussa; laminesaid@yahoo.fr

Received 8 February 2014; Revised 27 April 2014; Accepted 12 May 2014; Published 29 May 2014

Academic Editor: Himanshu Garg

Copyright (C) 2014 Paul Attien et al. This is an open access article distributed under the Creative Commons Attribution License, which permits unrestricted use, distribution, and reproduction in any medium, provided the original work is properly cited.

\begin{abstract}
The aim of our study was to investigate the microbial quality of meat products and on some clinical samples in Abidjan focused on Staphylococcus genus and the toxin production profile of Staphylococcus aureus (S. aureus) isolated. Bacteria were collected from 240 samples of three meat products sold in Abidjan and 180 samples issued from clinical infections. The strains were identified by both microbiological and MALDI-TOF-MS methods. The susceptibility to antibiotics was determined by the disc diffusion method. The production of Panton-Valentine Leukocidin, LukE/D, and epidermolysins was screened using radial gel immunodiffusion. The production of staphylococcal enterotoxins and TSST-1 was screened by a Bio-Plex Assay. We observed that 96/240 of meat samples and 32/180 of clinical samples were contaminated by Staphylococcus. Eleven species were isolated from meats and 4 from clinical samples. Forty-two S. aureus strains were isolated from ours samples. Variability of resistance was observed for most of the tested antibiotics but none of the strains displays a resistance to imipenem and quinolones. We observed that $89 \%$ of clinical S. aureus were resistant to methicillin against $58 \%$ for those issued from meat products. All S. aureus isolates issued from meat products produce epidermolysins whereas none of the clinical strains produced these toxins. The enterotoxins were variably produced by both clinical and meat product samples.
\end{abstract}

\section{Introduction}

S. aureus is a bacterial pathogen distributed worldwide and a leading cause of morbidity and mortality. S. aureus is the most abundant member of the indigenous flora of human skin [1]. It causes a variety of infections ranging from mild to severe diseases, life-threatening conditions [2]. This versatile pathogen has evolved to a remarkable ability to 
resist antibiotics such as methicillin and other beta-lactams, glycopeptides, fluoroquinolones, and aminoglycosides, complicating the management of diseases [3].

Indeed, until the 1990s, methicillin resistance was recognized as a specific trait of healthcare-associated $S$. aureus (HA-MRSA), which was first described in the early 1960s [4]. But, methicillin-resistant S. aureus (MRSA) strains spread throughout the world, first in hospital settings, but also in the community [5]. It has been reported that $8 \%$ of healthy human adults are colonized with MRSA [6]. Apart from resistance, the pathogenicity of $S$. aureus is related to exhaustive vast arsenal of virulence factors and toxins that mainly counteract innate immunity to avoid further adaptive immunity [7].

Among those factors are exotoxins responsible for human infections such as exfoliative toxins (ETs), toxic shock syndrome toxin-1 (TSST-1), staphylococcal enterotoxins (SEs), leukocidins (PVL, LukE/D) and haemolysins $(\alpha, \beta, \gamma, \delta)[8]$. Enterotoxins are often the cause of food poisoning [9] while exfoliative toxins (also call epidermolysins) act upon the skin [10]. S. aureus can be found as well in clinical sample as on ready-to-eat foods. Thus, $S$. aureus can be isolated in most of the biological samples $[11,12]$.

Concerning foods, according to Dennaï et al. [13] and Fosse et al. [14], meat has been traditionally regarded as a vehicle for many foodborne diseases in humans. Its hygienic quality depends on the contamination occurring during slaughtering and cutting process and the development and growth of these biocontaminants during cooling, storage, and distribution $[13,15]$.

In many tropical countries foods are commonly sold at all public places and roadside shops. However, in view of their ready consumption, quick methods of cleaning and handling them might often constitute a public health threat. In addition, the slaughterhouses are one of the main critical points of meat hygiene and they are considered to be the stage where the greatest opportunities of contamination may occur [16]. According to Jouve [17], $80 \%$ to $90 \%$ of the microflora of meat reaching the consumers resulted from contamination occurring at the slaughterhouse. The pathogenicity and the resistance profile of Ivoirians Staphylococcus are not yet known because strains are not clearly identified and defined. This lack of information makes the establishment of the impact of such bacteria in the pathologies where they are involved difficult. The aim of our present study was to investigate the resistance to antibiotic and toxin production of $S$. aureus isolated from clinical samples and meat products collected in Abidjan, Cote D'Ivoire.

\section{Material and Methods}

\subsection{Sample Collection}

2.1.1. Foods Samples. From November 2009 to March 2011, three kinds of meat (beef, pork, and chicken) were collected in the four most popular sectors of Abidjan (Abobo, Yopougon, Adjamé, and Treichville). At each sector, four places were selected regarding their high diurnal and nocturnal people frequentation. Meat products samples were collected from street sellers as braised meat. One sample of each kind of meat (beef, pork, and chicken) was collected five times (one per month) at each site. For the whole study, 240 samples with 80 samples (20 samples per site) of each kind of meat products were collected. The samples were collected in sterile Stomacher papers then carried to laboratory in icebox at $<4^{\circ} \mathrm{C}$.

2.1.2. Clinical Samples. The clinical strains were collected from 180 biological samples and carried to the bacteriology unit of the University Hospital of Treichville (Cote D'Ivoire) for various routine bacteriological screenings, from November 2009 to March 2011. According to their site of collection, the collected biological samples were pooled in three groups: (i) patients having pus and serositises, (ii) patient with urogenital infections (urine, vaginal, and urethral), and (iii) mucous membrane (skin and nostril) of healthy persons. During these seventeen months of our study, seventy samples of each group were collected. A part of urine samples we collected in sterile tubes, the other samples were collected with swabs.

\subsection{Microbiological Analysis}

2.2.1. Foods Samples. Once at the laboratory, $10 \mathrm{~g}$ of each food sample was homogenized in $90 \mathrm{~mL}$ of sterile bacteriological peptone (Oxoid, Hampshire, UK) and then was incubated at $37^{\circ} \mathrm{C}$ for 1 to $3 \mathrm{~h}$ [17]. To perform the isolation of Staphylococcus strains, $0.1 \mathrm{~mL}$ of serial decimal dilutions was plated in duplicate on Baird-Parker Agar medium (Biolab, South Africa) with $50 \mathrm{~mL}$ egg-yolk tellurite emulsion (Merck, Darmstadt, Germany) and incubated at $37^{\circ} \mathrm{C}$ for $48 \mathrm{~h}$.

2.2.2. Clinical Samples. The swabs were directly streaked on specific medium. For the urine samples, $1 \mu \mathrm{L}$ was streaked onto surface of blood agar and Cystine-Lactose Electrolyte Deficient (CLED) agar using standard wire loop. All the plates were incubated at $37^{\circ} \mathrm{C}$ for $24 \mathrm{~h}$.

2.3. Microorganism Identification. Standard microbiological methods for microorganism's identification were used [18]. Then, S. aureus identification was based on Gram staining, morphology, catalase positivity (ID color Catalase; bioMérieux, Marcy l'Etoile, France), agglutination in the Pastorex Staph Plus test (Bio-Rad, Marnes la Coquette, France), and free coagulase production with lyophilized rabbit plasma [19]. Finally, the isolates were confirmed by API Staph (bioMérieux, Marcy l'Etoile, France).

\subsection{MALDI-TOF Mass Spectrometry. MALDI-TOF mass} spectrometry was used to confirm the microbial identification. The direct identification of bacteria by the MALDITOF/MS was serially processed in parallel of the routine protocol. The bacterial pellet was treated with the standard ethanol/formic acid protein extraction protocol before MALDI-TOF identification using a Biflex III mass spectrometer and Flex-analysis, MALDI-Biotyper, software solutions 
TABle 1: Contamination level of meat products and clinical samples collected in Abidjan, Cote D'Ivoire.

\begin{tabular}{|c|c|c|c|c|c|c|c|}
\hline \multirow{2}{*}{ Species } & \multicolumn{3}{|c|}{$\begin{array}{l}\text { Percentage of meat samples } \\
\text { contamination }(n=96)\end{array}$} & \multicolumn{3}{|c|}{$\begin{array}{l}\text { Percentage of clinical samples } \\
\text { contamination }(n=32)\end{array}$} & \multirow{2}{*}{ Total $(n=128)$} \\
\hline & $\begin{array}{c}\text { Beef } \\
(n=27)\end{array}$ & $\begin{array}{c}\text { Pork } \\
(n=22)\end{array}$ & $\begin{array}{l}\text { Chickens } \\
(n=47)\end{array}$ & $\begin{array}{c}\text { Pus/Serositises } \\
\quad(n=19)\end{array}$ & $\begin{array}{l}\text { Urogenital } \\
(n=07)\end{array}$ & $\begin{array}{l}\text { Healthy persons } \\
\qquad(n=06)\end{array}$ & \\
\hline S. sciuri & $9 \%(9)$ & $4 \%(4)$ & $20 \%(19)$ & $6 \%(2)$ & $0 \%(0)$ & $9 \%(3)$ & $28.9 \%(37)$ \\
\hline S. aureus & $13 \%(12)$ & $5 \%(5)$ & $2 \%(2)$ & $44 \%(14)$ & $19 \%(6)$ & $9 \%(3)$ & $32.8 \%(42)$ \\
\hline S. simulans & $1 \%(1)$ & $6 \%(6)$ & $8 \%(8)$ & $0 \%(0)$ & $0 \%(0)$ & $0 \%(0)$ & $11.7 \%(15)$ \\
\hline S. xylosus & $1 \%(1)$ & $4 \%(4)$ & $7 \%(7)$ & $0 \%(0)$ & $3 \%(1)$ & $0 \%(0)$ & $10 \%(13)$ \\
\hline S. cohnii & $0 \%(0)$ & $1 \%(1)$ & $4 \%(4)$ & $0 \%(0)$ & $0 \%(0)$ & $0 \%(0)$ & $4 \%(5)$ \\
\hline S. lentus & $0 \%(0)$ & $1 \%(1)$ & $3 \%(3)$ & $0 \%(0)$ & $0 \%(0)$ & $0 \%(0)$ & $3 \%(4)$ \\
\hline S. haemolyticus & $3 \%(3)$ & $0 \%(0)$ & $0 \%(0)$ & $6 \%(2)$ & $0 \%(0)$ & $0 \%(0)$ & $4 \%(5)$ \\
\hline S. saprophyticus & $1 \%(1)$ & $1 \%(1)$ & $0 \%(0)$ & $0 \%(0)$ & $0 \%(0)$ & $0 \%(0)$ & $1.6 \%(2)$ \\
\hline S. capitis & $0 \%(0)$ & $0 \%(0)$ & $2 \%(2)$ & $3 \%(1)$ & $0 \%(0)$ & $0 \%(0)$ & $2 \%(3)$ \\
\hline S. succinus & $0 \%(0)$ & $0 \%(0)$ & $1 \%(1)$ & $0 \%(0)$ & $0 \%(0)$ & $0 \%(0)$ & $1 \%(1)$ \\
\hline S. equorum & $0 \%(0)$ & $0 \%(0)$ & $1 \%(1)$ & $0 \%(0)$ & $0 \%(0)$ & $0 \%(0)$ & $1 \%(1)$ \\
\hline
\end{tabular}

(Biotyper System, Bruker Daltonics) for analysis of acquired data $[20,21]$.

2.5. Antibiotics Susceptibility. Antimicrobial susceptibility was determined by the disc diffusion method of KirbyBauer on agar Mueller-Hinton (bioMérieux, Marcy l'Etoile, France) as recommended by the Antibiogram Committee of the French Microbiology Society [22]. After $24 \mathrm{~h}$ at $37^{\circ} \mathrm{C}$, inhibition zone was measured. For susceptibility to oxacillin, inoculum of $10^{7} \mathrm{CFU} / \mathrm{mL}$ was prepared, and the plate was incubated at $37^{\circ} \mathrm{C}$ for $24 \mathrm{~h}$ on MuellerHinton agar $+2 \% \mathrm{NaCl}$. The tested antibiotics (BioRad, Marne la Coquette, France) were Pristinamycin, Erythromycin, Lincomycin, Oxacillin, Amoxicillin, Ceftriaxone, Gentamicin, Tobramycin, Sisomicin, Oxytétracycline, Tetracycline, Trimethoprim/sulfonamides, Cefotaxime, Ofloxacine, Pefloxacin, Vancomycin, Rifampicin, and Imipenem.

\subsection{Toxins Production}

2.6.1. Phenotypic Detection of Toxins. For the phenotypic detection of toxins radial gel immunodiffusion was performed. The production of Panton-Valentine Leukocidin (PVL) and epidermolysins A (ETA) and B (ETB) was evidenced from culture supernatants after $18 \mathrm{~h}$ of growth in Yeast Casamino-acid Pyruvate (YCP) medium [23] by radial gel immunodiffusion in $0.6 \%$ (wt/vol) agarose with componentspecific rabbit polyclonal and affinity-purified antibodies [24, 25].

2.6.2. Staphylococcal Enterotoxins Production by Bio-Plex Assay (xMAP Multiplex Assay). The centrifuged supernatant $\left(3 \mathrm{~mL}\right.$ ) of $S$. aureus grown on $\mathrm{BHI}$ at $37^{\circ} \mathrm{C}$ (night) was recovered and diluted $1 / 2$ in TBS-Tween $20(0.05 \%)$-nonspecific rabbit IgG at $100 \mu \mathrm{g} / \mathrm{mL}$, and incubated for $30 \mathrm{~min}$ at room temperature $\left(25^{\circ} \mathrm{C}\right)$. The Bio-Plex Assays consisted of three incubation steps that were performed into flat-bottom Multiscreen microplates (pores diameter $=1.2 \mu \mathrm{m}$, Millipore) according to the previously describe method [26]. Any steps were separated by three washes into TBS-Tween 20. Enterotoxin SEA, SEB, SEC, SED, SEE, SEG, SEH, and SEI were screening by this method in this study.

2.7. Data Analysis. For comparison tests of positive isolates in various samples, Student's $t$-test, and Fischer's test were used for lower number series (GraphPad Prism 5). $P<0.05$ was considered statistically significant.

\section{Results}

3.1. Bacterial Identification. Our data reveal the presence of Staphylococcus sp. in both clinical and meat product samples. Globally, in our study (Table 1), S. aureus is isolated in 42/128 (32.81\%) followed by S. sciuri $(28.90 \%)$. Nevertheless, there were isolated 11 Staphylococcus species in meat products and 5 species in clinical tested samples (Table 1). Regarding the 96 meat samples (over 240 samples) contaminated by Staphylococcus species, the isolated rate of the 11 species was S. sciuri (33\%), S. aureus (20\%), S. simulans (16\%), S. xylosus (12.50\%), S. cohnii (5\%), S. lentus (4\%), S. haemolyticus (3\%), S. saprophyticus (2\%), S. capitis (2\%), S. succinus (1\%), and S. equorum (1\%). For the clinical samples, among the 32 contaminated ones (over 180 samples), the four following species were isolated: S. aureus, S. xylosus, S. haemolyticus, and S. capitis (Table 1).

3.2. Antibiotics Susceptibility. The susceptibility of S. aureus strains varies depending on antibiotic tested and the origin of the strains (Figure 1). We thus observe for the clinical strains high resistance level to Oxy-tetracycline (100\%), Erythromycin (97\%), Oxacillin (89\%), and Ceftriaxone (81\%). There was a very low resistance level of the clinical strain to 


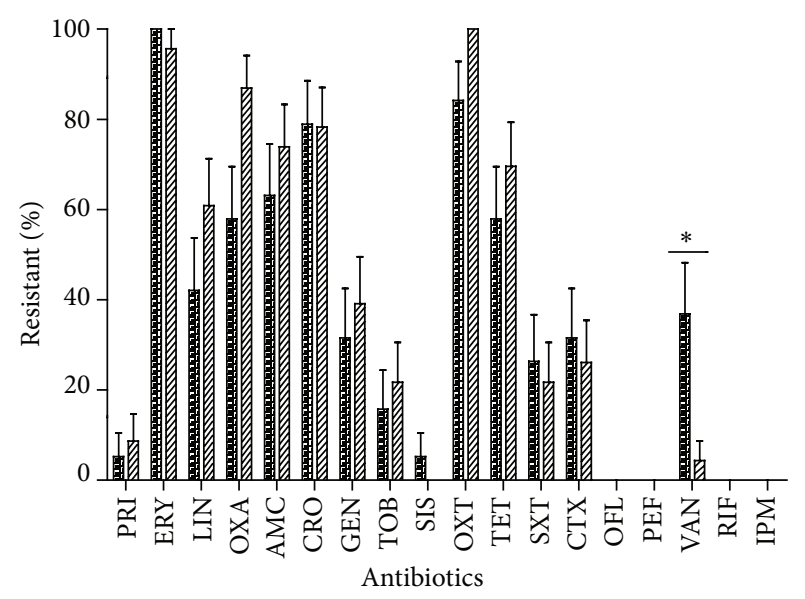

Figure 1: Resistance profile to 18 antibiotics of Staphylococcus aureus strains isolated from clinical and meat samples. PRIS: Pristinamycin; ERY: Erythromycin; LIN: Lincomycin; OXA: Oxacillin; AMC: Amoxicillin; CRO: Ceftriaxone; GEN: Gentamicin; TOB: Tobramycin; SIS: sisomicin; OXT: Oxytetracycline; TET: Tetracycline; SXT: Trimethoprim/sulfonamides; CTX: Cefotaxime; OFL: Ofloxacine; PEF: Pefloxacin; VAN: Vancomycin; RIF: Rifampicin; and IPM: Imipenem. ${ }^{*} P<0.05$.

7/18 antibiotics: Imipenem (0\%), Rifampicin (0\%), Ofloxacin (0\%), Pefloxacin (0\%), Sisomicin (0\%), Pristinamycin, and Vancomycin. The same resistance profile was observed with strains isolated from meats but there was variation of resistance proportions. Then, we observed the highest resistance level with Erythromycin (100\%), Oxytetracycline (84\%), Ceftriaxone (79\%), and Oxacillin (58\%). We therefor observed a very high level of vancomycin resistance (37\%) among meat products isolates. This proportion is statistically higher than the $4 \%$ of resistance among clinical strains $(P<0.05)$. The most active antibiotics on $S$. aureus isolated from meat product were Imipenem (0\%), Rifampicin (0\%), Ofloxacin $(0 \%)$, Pefloxacin (0\%), Pristinamycin, and Sisomicin.

3.3. Production of Toxins. Our data display a variability of toxins production according to origin $(P<0.0001)$. Globally, $S$. aureus isolated from meat products produced more toxins than those isolated from clinical samples (Figure 2). The epidermolysins were exclusively produced by meat isolated strains $(P<0.0001)$.

Thus, the food isolates produced 10 of the 13 tested toxins. The epidermolysins A (100\%) and B (89.5\%) were the most produced followed by enterotoxins I (68.4\%) G (47.4\%). Among the strains isolated from meats, the toxins production was highly different $(P<0.0001)$. Regarding the kind of meat, we observed a difference of toxins production. Indeed, isolates from beef products produced 9 over the 13 sought toxins when those isolated from pork and chicken meat produced 7 over 13 (Figure 3(a)).

Considering the clinical strains, we noted the production of 11 of the 13 tested toxins. For these clinical strains, PVL and

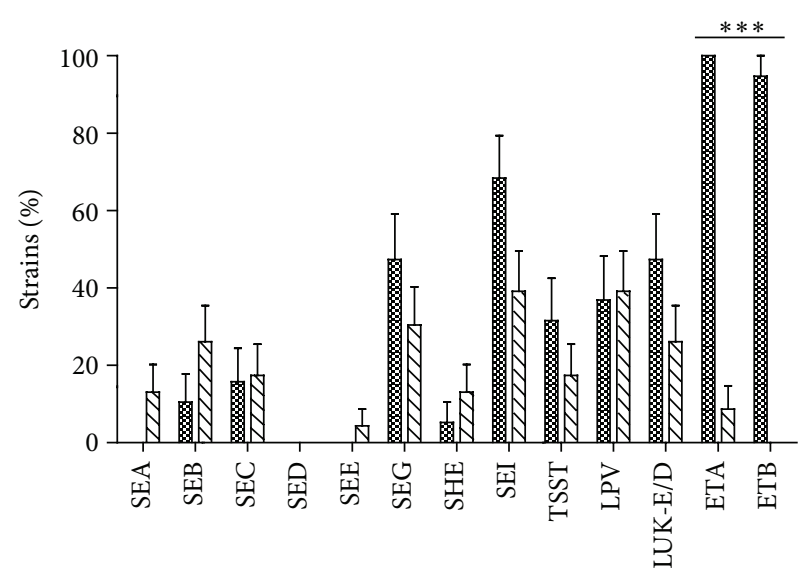

\footnotetext{
Toxins of S.aureus

$\triangle$ Clinical strains

Meat strains
}

Figure 2: Profile of toxins production by the S. aureus strains isolated from clinical and meat samples. SEA: staphylococcal enterotoxin A; SEB: staphylococcal enterotoxin B; SEC: staphylococcal enterotoxin C; SED: staphylococcal enterotoxin D; SEE: staphylococcal enterotoxin E; SEG: staphylococcal enterotoxin G; SEH: staphylococcal enterotoxin H; SEI: staphylococcal enterotoxin I; TSST: Toxic-shock syndrome Toxin; PVL: Panton-Valentine Leukocidin; Luk-E/D: Leukotoxin E/D; ETA: Exfoliative Toxin A; ETB: Exfoliative Toxin B. ${ }^{* * *} P<0.0001$.

enterotoxin I were the most often produced toxin (39.1\%). Most of the toxins were produced by few clinical strains (Figure 2). According to the origin of the strains, we observed a slight variation in toxins production. Thus, the PVL was not produced by the isolates issued from healthy persons and the highest level was observed with the samples from pus and serositises (Figure 3(b)).

\section{Discussion}

4.1. Bacterial Identification. The first part of our work was to identify the Staphylococcus species isolated from clinical samples collected in some hospitals of Abidjan (Cote D'Ivoire) and three kinds of meat sold in Abidjan. Table 1 indicates that food samples were the most contaminated by S. aureus strains, despite being cooked at the sampling time. Indeed, from meat samples, 11 different species were isolated whereas in clinical samples we isolated 5 species. Then, 10 different coagulase negative staphylococci (CNS) species were found in our meat samples and 4 in the clinical ones. The number of species identified in our study is higher than those isolated in Croatia in fermented sausage [27]. The nature of meat product can explain the observed difference in terms of number of species. In fact, the process used to prepare fermented sausages needs more steps than our meat sample. Then, during the manufacturing of fermented sausages, some species are destroyed. The great number of coagulase negative staphylococci (CNS) in meat samples (10 species) in comparison with clinical ones [28] can be explained by the fact that those CNS are commonly used for meat fermentation. 


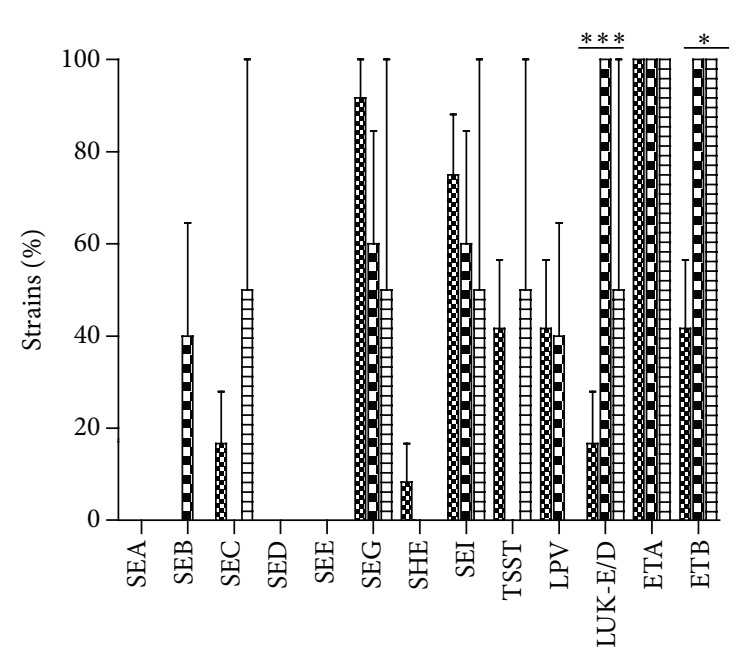

Toxins of S.aureus

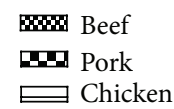

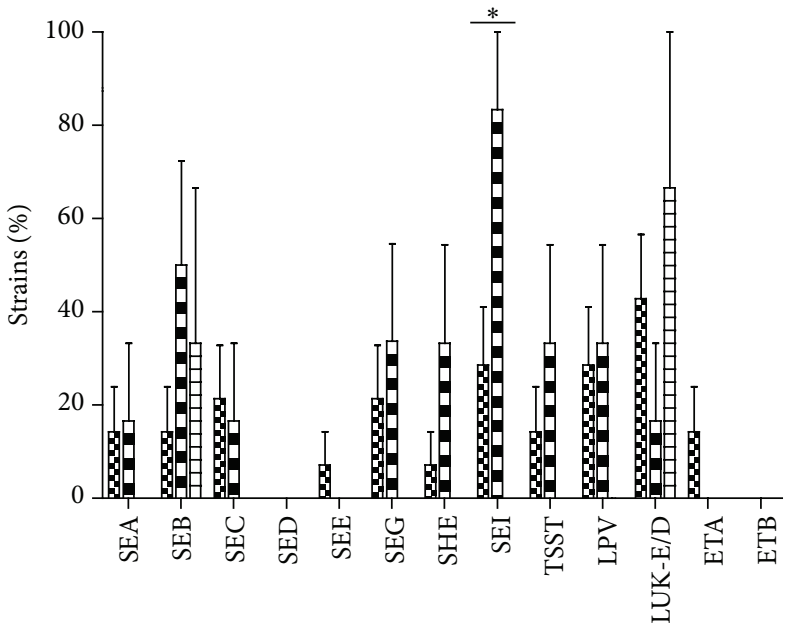

Toxins of S.aureus

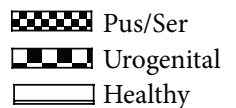

(a)

(b)

Figure 3: Specificity of the toxins production by the S. aureus strains isolated from meat (a) and clinical (b) samples according to their origin. SEA: staphylococcal enterotoxin A; SEB: staphylococcal enterotoxin B; SEC: staphylococcal enterotoxin C; SED: staphylococcal enterotoxin D; SEE: staphylococcal enterotoxin E; SEG: staphylococcal enterotoxin G; SEH: staphylococcal enterotoxin H; SEI: staphylococcal enterotoxin I; TSST: Toxic-shock syndrome Toxin; PVL: Panton-Valentine Leukocidin; Luk-E/D: Leukotoxin E/D, ETA: Exfoliative Toxin A; ETB: Exfoliative Toxin B. ${ }^{*} P<0.05,{ }^{* * *} P<0.0001$.

Indeed, CNS such as S. xylosus [29], S. equorum, and S. saprophyticus [30-32] have been reported all over the world in fermented meats as starter cultures $[33,34]$. The CNS species are isolated from both meat chain production and final meat products [35]. Then, we can estimate that most of the CNS isolates are useful in the fermentation process of the meats products sold in the streets of Abidjan. These CNS are potentially less pathogenic and may be part of the skin flora, and they hold rarely toxigenic component [36]; we must nevertheless pay attention because these bacterial develop resistance to many antibiotic molecules [37].

4.2. Antibiotics Susceptibility. The second part of our work aims at studying the antibiotics susceptibility of $S$. aureus isolated from clinical and meat samples to 18 antibiotics. Figure 1 showing the resistance profile of the $42 \mathrm{~S}$. aureus strains indicates variability according to the antibiotics and the origin of the strains. For both clinical and food isolated $S$. aureus strains, the highest resistance levels were observed with Oxy-tetracycline, Erythromycin, Oxacillin, and Ceftriaxone. Our data display a high resistance level to macrolides and $\beta$-Lactamines. The observed high proportions can be the effect of excessive use of invalid antibiotics and traditional medicine out of the hospital area; that contributes to selecting resistant strains in the community.

Our data show a high proportion of $S$. aureus strains resistant to oxacillin independently of their origin. This proportion of $89 \%$ for clinical strains and $58 \%$ for meat strains observed increase steadily in Cote D'Ivoire. Indeed, in 2012
Zinzendorf et al. [38] observed less than $20 \%$ of S. aureus resistance to methicillin in a Military Hospital at Abidjan (Cote D'Ivoire). The observed gap with this study can be explained by the variability of our stains. Indeed, our strains were isolated from various kinds of clinical and meat samples. Another explanation, that is, the difference of methodology, may be outlined because these authors used the molecular approach, whereas we used the disc diffusion method. Then, analyzing this result, the efficacy of the formerly indicated that molecule against $S$. aureus strains is decreasing [39].

A high level of vancomycin resistance (37\%) among meat products isolates in comparison to the clinical isolates $(P<0.05)$ was observed. In hospitals, where higher selective pressure is normally present, vancomycin is one of the antibiotics used to treat multiresistance $S$. aureus strains. This surprising result may be an effect of invalid use of antibiotics to treat suspected food poisoning or farm animal infections in this area. Another possible reason of this difference may be explained by the fact that, in this area, farmers currently use an excess of the glycopeptides avoparcin as a growth promoter in food-producing animals indicating that these animals might be a potential reservoir for vancomycin resistance determinants [40-42].

4.3. Production of Toxins. Figure 2 indicated the distribution of 13 toxins usually produced by $S$. aureus strains according to their origin $(P<0.0001)$. Indeed, comparing with their origins (clinical and meat), clinical isolated strains produce 11 of the 13 sought toxins when meat isolated ones 
produced 10 of 13 . Concerning the isolates issued from meat products, the epidermolysins A (100\%) and B (89.5\%) were the most produced followed by enterotoxins I (68.4\%) and G (47.4\%). Among the strains isolated from meats, the toxins production was highly different $(P<0.0001)$. The high level of epidermolysins indicates that these isolates in meat may be originated from an upstream phase of preparation, such as the handling of the meat sealers or the unsterile containers. We should remark that the meats are usually sold in papers package (mainly cement package paper). Indeed, epidermolysins are known to be serine active proteases with their activity highly specialized on desmoglein-1, an important protein of child epidermis [43, 44]. Regarding the kind of meat, we observed that strains isolated from beefs produced 2 toxins (SEA and SEE) that were not produced by those isolated from pork and chicken meat (Figure 3(a)). Then, the high level of $S$. aureus producing epidermolysins in the beef samples can be explained by slaughtering contamination. In fact, beef consumed parts are generally separate from the animal skin which constitutes a filter of microorganisms. After removing the skin of beef, the consumed parts become exposed to the sellers' manual contamination during the transformation process. On the back of the epidermolysins production, we observe that enterotoxins and TSST-1 are strongly produced. These observations must attract our attention from probable food poisoning further to the consumption of meat sold in Abidjan streets. Indeed, enterotoxins are known to be associated with food poisoning [45-47]; they are also known to have superantigenic and emetic activities. Clinically, staphylococcal infection is a frequent cause of foodborne gastroenteritis in the world [48], following the ingestion of staphylococcal enterotoxins [49].

For the clinical strains, PVL and enterotoxin I were the most produced toxins (39.1\%). Most of the toxins were produced by few clinical isolates (Figure 2). Considering the origin of the isolates, we observe a slight variation on toxins production. Thus, the PVL and enterotoxin I was not produced by the strains isolated from healthy persons, but the highest incidence was observed with the samples of pus and serosities (Figure 3(b)). PVL appears to be a primordial toxin of clinical $S$. aureus isolates and particularly from skin, soft tissues, and bone-related infections [50]. Making a comparison with strains isolated from meats, those isolated from clinical field appear more pathogenic. It was documented that positive PVL S. aureus strains are more pathogenic than negative PVL ones $[51,52]$. In fact, the cell lysis spectrum of PVL affects directly the monocytes, macrophages, polynuclear neutrophils, and the metamyelocytes and some, at least, neurons [53, 54], although the erythrocytes are not lysed in their presence [55].

\section{Conclusion}

Human infections and meat products accommodate many Staphylococcus lineages. The susceptibility to antibiotics indicated the highest level of methicillin resistance among the $S$. aureus isolated from both clinical samples. The toxins production by $S$. aureus reveals that Panton-Valentine
Leukotoxin may be the most frequently produced toxin by clinical strains, whereas meat products were most often contaminated by epidermolysins and enterotoxins producers. Through the ability of strains isolated from meat products to produce enterotoxins, we, thus, demonstrate that meats sold in the streets of Abidjan can potentially be a source of food poisoning. This study should be deepened by studying in this area the direct relation between the street food $S$. aureus isolates and clinical infections suck like diarrhea using the genotyping.

\section{Conflict of Interests}

The authors declare that there is no conflict of interests regarding the publication of this paper.

\section{Acknowledgment}

This work was supported by Grant EA-4438 (G. Prévost) from "Direction de la Recherche et des Etudes Doctorales" of Strasbourg University (France).

\section{References}

[1] W. Tavares, "Bacterias gram-positivas problemas: resistência do estafilococo, do enterococo e do pneumococo aos antimicrobianos," Revista da Sociedade Brasileira Medicina Tropical, vol. 33, pp. 281-301, 2000.

[2] K. B. Crossley, K. K. Jefferson, G. L. Archer, and V. G. Fowler Jr., The Staphylococci in Human Disease, Wiley-Blackwell, West Sussex, UK, 2nd edition, 2009.

[3] N. G. Daver, S. A. Shelburne, R. L. Atmar et al., "Oral step-down therapy is comparable to intravenous therapy for Staphylococcus aureus osteomyelitis," Journal of Infection, vol. 54, no. 6, pp. 539544, 2007.

[4] M. P. Jevons, A. W. Coe, and M. T. Parker, "Methicillin resistance in staphylococci," The Lancet, vol. 281, no. 7287, pp. 904-907, 1963.

[5] O. Lesens, Y. Hansmann, E. Brannigan et al., "Healthcareassociated Staphylococcus aureus bacteremia and the risk for methicillin resistance: is the centers for disease control and prevention definition for community-acquired bacteremia still appropriate?" Infection Control and Hospital Epidemiology, vol. 26, no. 2, pp. 204-209, 2005.

[6] H. F. L. Wertheim, D. C. Melles, M. C. Vos et al., "The role of nasal carriage in Staphylococcus aureus infections," Lancet Infectious Diseases, vol. 5, no. 12, pp. 751-762, 2005.

[7] A. Zecconi and F. Scali, "Staphylococcus aureus virulence factors in evasion from innate immune defenses in human and animal diseases," Immunology Letters, vol. 150, no. 1-2, pp. 12-22, 2013.

[8] M. M. Dinges, P. M. Orwin, and P. M. Schlievert, "Exotoxins of Staphylococcus aureus," Clinical Microbiology Reviews, vol. 13, no. 1, pp. 16-34, 2000.

[9] N. L. Barg and T. Harris, "Toxin-mediated syndromes," in The Staphylococci in Human Disease, K. B. Crossley and G. L. Archer, Eds., pp. 527-544, Churchill Livingstone, New York, NY, USA, 1997.

[10] F. Durupt, L. Mayor, M. Bes et al., "Prevalence of Staphylococcus aureus toxins and nasal carriage in furuncles and impetigo," British Journal of Dermatology, vol. 157, no. 6, pp. 1161-1167, 2007. 
[11] L. Baba-Moussa, H. Ahissou, P. Azokpota et al., "Toxins and adhesion factors associated with Staphylococcus aureus strains isolated from diarrhoeal patients in Benin," African Journal of Biotechnology, vol. 9, no. 5, pp. 604-611, 2010.

[12] H. Sina, F. Baba-Moussa, T. A. Ahoyo et al., "Antibiotic susceptibility and toxins production of Staphylococcus aureus isolated from clinical samples from benin," African Journal of Microbiology Research, vol. 5, no. 18, pp. 2797-2803, 2011.

[13] N. Dennaï, B. Kharrati, and M. El Yachioui, "Appréciation de la qualité microbiologique des carcasses de bovins fraîchement abattus," Annales de Medecine Veterinaire, vol. 145, no. 4, pp. 270-274, 2001.

[14] J. Fosse, C. Magras, and H. Seegers, "Evaluation quantitative des risques biologiques pour le consommateur de viande de porc," Journees de la Recherche Porcine, vol. 39, pp. 207-214, 2007.

[15] S. El Okki, R. El Groud, H. Kenana, and S. Quessy, "Evaluation de la contamination superficielle des carcasses bovines et ovines provenant de l'abattoir municipal de Constantine en Algérie," The Canadian Veterinary Journal, vol. 200, pp. 638-640, 2005.

[16] J.-F. Collobert, F. Dorey, V. Dieuleveux, and N. Quillien, "Microbiological contamination of bovine carcasses," Sciences des Aliments, vol. 22, no. 3, pp. 327-334, 2002.

[17] J. L. Jouve, "Microbiologie alimentaire et filière des viandes," Viandes et Produits Carnés, vol. 116, no. 6, pp. 207-213, 1990.

[18] J.-F. T. K. Akoachere, R. N. Bughe, B. O. Oben, L. M. Ndip, and R. N. Ndip, "Phenotypic characterization of human pathogenic bacteria in fish from the coastal waters of south west Cameroon: public health implications," Reviews on Environmental Health, vol. 24, no. 2, pp. 147-156, 2009.

[19] M. Cheesbrough, District Laboratory Practice in Tropical Countries: Part 2, Cambridge University Press, Cambridge, UK, 2004.

[20] A. Mellmann, F. Bimet, C. Bizet et al., "High interlaboratory reproducibility of matrix-assisted laser desorption ionizationtime of flight mass spectrometry-based species identification of nonfermenting bacteria," Journal of Clinical Microbiology, vol. 47, no. 11, pp. 3732-3734, 2009.

[21] G. Prod'Hom, A. Bizzini, C. Durussel, J. Bille, and G. Greub, "Matrix-assisted laser desorption ionization-time of flight mass spectrometry for direct bacterial identification From positive blood culture pellets," Journal of Clinical Microbiology, vol. 48, no. 4, pp. 1481-1483, 2010.

[22] SFM (Société Française de Microbiologie), Recommandations du Comité de l'Antibiogramme de la Société Française de Microbiologie, 2012.

[23] V. Gauduchon, S. Werner, G. Prévost, H. Monteil, and D. A. Colin, "Flow cytometric determination of Panton-Valentine leucocidin S component binding," Infection and Immunity, vol. 69, no. 4, pp. 2390-2395, 2001.

[24] G. Prevost, P. Couppie, P. Prevost et al., "Epidemiological data on Staphylococcus aureus strains producing synergohymenotropic toxins," Journal of Medical Microbiology, vol. 42, no. 4, pp. 237-245, 1995.

[25] A. Gravet, D. A. Colin, D. Keller, R. Girardot, H. Monteil, and G. Prévost, "Characterization of a novel structural member, LukELukD, of the bi-component staphylococcal leucotoxins family," FEBS Letters, vol. 436, pp. 202-208, 1998.

[26] O. Joubert, D. Keller, A. Pinck, H. Monteil, and G. Prévost, "Sensitive and specific detection of staphylococcal epidermolysins A and B in broth cultures by flow cytometry-assisted multiplex immunoassay," Journal of Clinical Microbiology, vol. 43, no. 3, pp. 1076-1080, 2005.
[27] N. Zdolec, I. Rači, A. Vujnović et al., "Antimicrobial resistance of coagulase-negative staphylococci isolated from spontaneously fermented sausages," Food Technology and Biotechnology, vol. 51, no. 2, pp. 240-246, 2013.

[28] R. Talon and S. Leroy, "Diversity and safety hazards of bacteria involved in meat fermentations," Meat Science, vol. 89, no. 3, pp. 303-309, 2011.

[29] M. Seitter, C. Nerz, R. Rosenstein, F. Götz, and C. Hertel, "DNA microarray based detection of genes involved in safety and technologically relevant properties of food associated coagulase-negative staphylococci," International Journal of Food Microbiology, vol. 145, no. 2-3, pp. 449-458, 2011.

[30] B. Martín, M. Garriga, M. Hugas, S. Bover-Cid, M. T. VecianaNogués, and T. Aymerich, "Molecular, technological and safety characterization of Gram-positive catalase-positive cocci from slightly fermented sausages," International Journal of Food Microbiology, vol. 107, no. 2, pp. 148-158, 2006.

[31] M. G. Bonomo, A. Ricciardi, T. Zotta, M. A. Sico, and G. Salzano, "Technological and safety characterization of coagulase-negative staphylococci from traditionally fermented sausages of Basilicata region (Southern Italy)," Meat Science, vol. 83, no. 1, pp. 15-23, 2009.

[32] E. Marty, J. Buchs, E. Eugster-Meier, C. Lacroix, and L. Meile, "Identification of staphylococci and dominant lactic acid bacteria in spontaneously fermented Swiss meat products using PCRRFLP," Food Microbiology, vol. 29, no. 2, pp. 157-166, 2012.

[33] N. Zdolec, M. Hadžiosmanović, L. Kozačinski et al., "Microbial and physicochemical succession in fermented sausages produced with bacteriocinogenic culture of Lactobacillus sakei and semi-purified bacteriocin mesenterocin Y," Meat Science, vol. 80, no. 2, pp. 480-487, 2008.

[34] M. G. Bonomo, A. Ricciardi, and G. Salzano, "Influence of autochthonous starter cultures on microbial dynamics and chemical-physical features of traditional fermented sausages of Basilicata region," World Journal of Microbiology and Biotechnology, vol. 27, no. 1, pp. 137-146, 2011.

[35] D. Simeoni, L. Rizzotti, P. Cocconcelli, S. Gazzola, F. Dellaglio, and S. Torriani, "Antibiotic resistance genes and identification of staphylococci collected from the production chain of swine meat commodities," Food Microbiology, vol. 25, no. 1, pp. 196201, 2008.

[36] S. Even, S. Leroy, C. Charlier et al., "Low occurrence of safety hazards in coagulase negative staphylococci isolated from fermented foodstuffs," International Journal of Food Microbiology, vol. 139, no. 1-2, pp. 87-95, 2010.

[37] P. Attien, H. Sina, W. Moussaoui et al., "Prevalence and antibiotic resistance of Staphylococcus strains isolated from meat products sold in Abidjan streets (Ivory Coast)," African Journal of Microbiology Research, vol. 7, no. 26, pp. 3285-3293, 2013.

[38] N. Y. Zinzendorf, A. Krizo, L. Baba-Moussa, V. Edoh, and Y. G. Loukou, "Molecular characteristics of Staphylococcus aureus from Military Hospital in Abidjan, Côte d'Ivoire," Bulletin of Environment, Pharmacology and Life Sciences, vol. 1, no. 7, pp. 54-58, 2012.

[39] H. Belabbès, N. Elmdaghri, K. Hachimi, L. Marih, K. Zerouali, and M. Benbachir, "Antibiotic resistance of Staphylococcus aureus isolated from community and nosocomial infections in casablanca," Medecine et Maladies Infectieuses, vol. 31, no. 1, pp. 25-28, 2001.

[40] W. Bustamante, A. Alpízar, S. Hernández et al., "Predominance of vanA genotype among vancomycin-resistant Enterococcus 
isolates from poultry and swine in Costa Rica," Applied and Environmental Microbiology, vol. 69, no. 12, pp. 7414-7419, 2003.

[41] H. Kruse, B. K. Johansen, L. M. Rørvik, and G. Schaller, "The use of avoparcin as a growth promoter and the occurrence of vancomycin-resistant Enterococcus species in Norwegian poultry and swine production," Microbial Drug Resistance, vol. 5, no. 2, pp. 135-139, 1999.

[42] J. M. Manson, J. M. B. Smith, and G. M. Cook, "Persistence of vancomycin-resistant enterococci in New Zealand broilers after discontinuation of avoparcin use," Applied and Environmental Microbiology, vol. 70, no. 10, pp. 5764-5768, 2004.

[43] S. Ladhani, "Understanding the mechanism of action of the exfoliative toxins of Staphylococcus aureus," FEMS Immunology and Medical Microbiology, vol. 39, no. 2, pp. 181-189, 2003.

[44] G. Prévost, P. Couppié, and H. Monteil, "Staphylococcal epidermolysins," Current Opinion in Infectious Diseases, vol. 16, no. 2, pp. 71-76, 2003.

[45] C. A. Morris, H. D. Conway, and P. H. Everall, "Food-poisoning due to staphylococcal enterotoxin E," The Lancet, vol. 2, no. 7791, pp. 1375-1376, 1972.

[46] T.-R. Chen, C.-S. Chiou, and H.-Y. Tsen, "Use of novel PCR primers specific to the genes of staphylococcal enterotoxin $G$, $\mathrm{H}$, I for the survey of Staphylococcus aureus strains isolated from food-poisoning cases and food samples in Taiwan," International Journal of Food Microbiology, vol. 92, no. 2, pp. 189-197, 2004.

[47] T. Ikeda, N. Tamate, K. Yamaguchi, and S.-I. Makino, "Mass outbreak of food poisoning disease caused by small amounts of staphylococcal enterotoxins A and H," Applied and Environmental Microbiology, vol. 71, no. 5, pp. 2793-2795, 2005.

[48] X. Yan, B. Wang, X. Tao et al., "Characterization of Staphylococcus aureus strains associated with food poisoning in Shenzhen, China," Applied and Environmental Microbiology, vol. 78, no. 18, pp. 6637-6642, 2012.

[49] J.-A. Hennekinne, M.-L. De Buyser, and S. Dragacci, "Staphylococcus aureus and its food poisoning toxins: characterization and outbreak investigation," FEMS Microbiology Reviews, vol. 36, no. 4, pp. 815-836, 2012.

[50] H. Sina, T. A. Ahoyo, W. Moussaoui et al., "Variability of antibiotic susceptibility and toxin production of Staphylococcus aureus strains isolated from skin, soft tissue, and bone related infections," BMC Microbiology, vol. 13, no. 1, article 188, 2013.

[51] Y. Gillet, B. Issartel, P. Vanhems et al., "Association between Staphylococcus aureus strains carrying gene for PantonValentine leukocidin and highly lethal necrotising pneumonia in young immunocompetent patients," The Lancet, vol. 359, no. 9308, pp. 753-759, 2002.

[52] L. Baba-Moussa, H. Sina, J.-M. Scheftel et al., "Staphylococcal panton-valentine leucocidin as a major virulence factor associated to furuncles," PLoS ONE, vol. 6, no. 10, Article ID e25716, 2011.

[53] G. P. Gladstone and W. E. Van Heyningen, "Staphylococcal leucocidins," British Journal of Experimental Pathology, vol. 38, no. 2, pp. 123-137, 1957.

[54] E. Jover, M. Y. Tawk, B.-J. Laventie, B. Poulain, and G. Prévost, "Staphylococcal leukotoxins trigger free intracellular $\mathrm{Ca}^{2+}$ rise in neurones, signalling through acidic stores and activation of store-operated channels," Cellular Microbiology, vol. 15, no. 5, pp. 742-758, 2013.

[55] G. Prévost, L. Mourey, D. A. Colin, and G. Menestrina, "Staphylococcal pore-forming toxins," Current Topics in Microbiology and Immunology, vol. 257, pp. 53-83, 2000. 

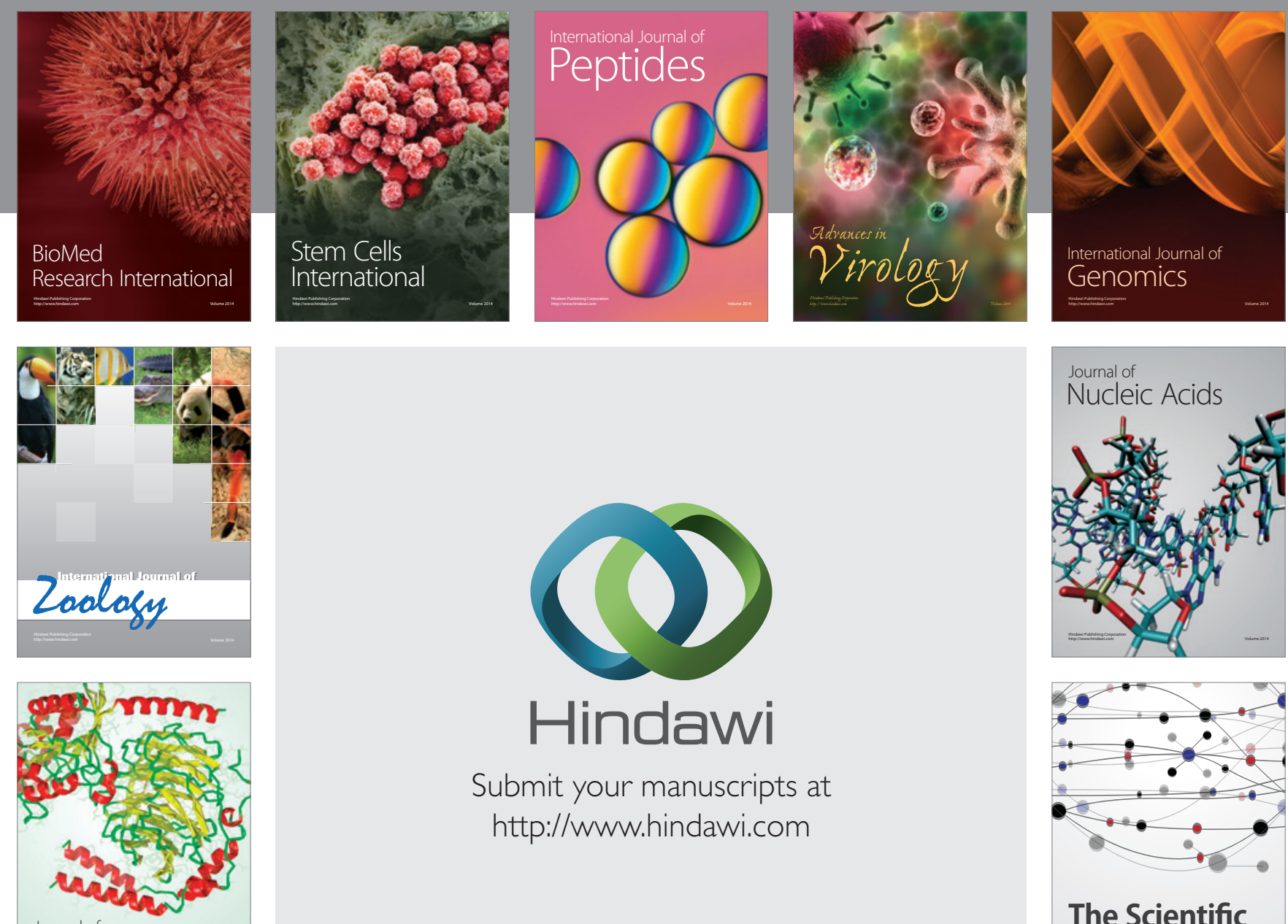

Submit your manuscripts at

http://www.hindawi.com

Journal of
Signal Transduction
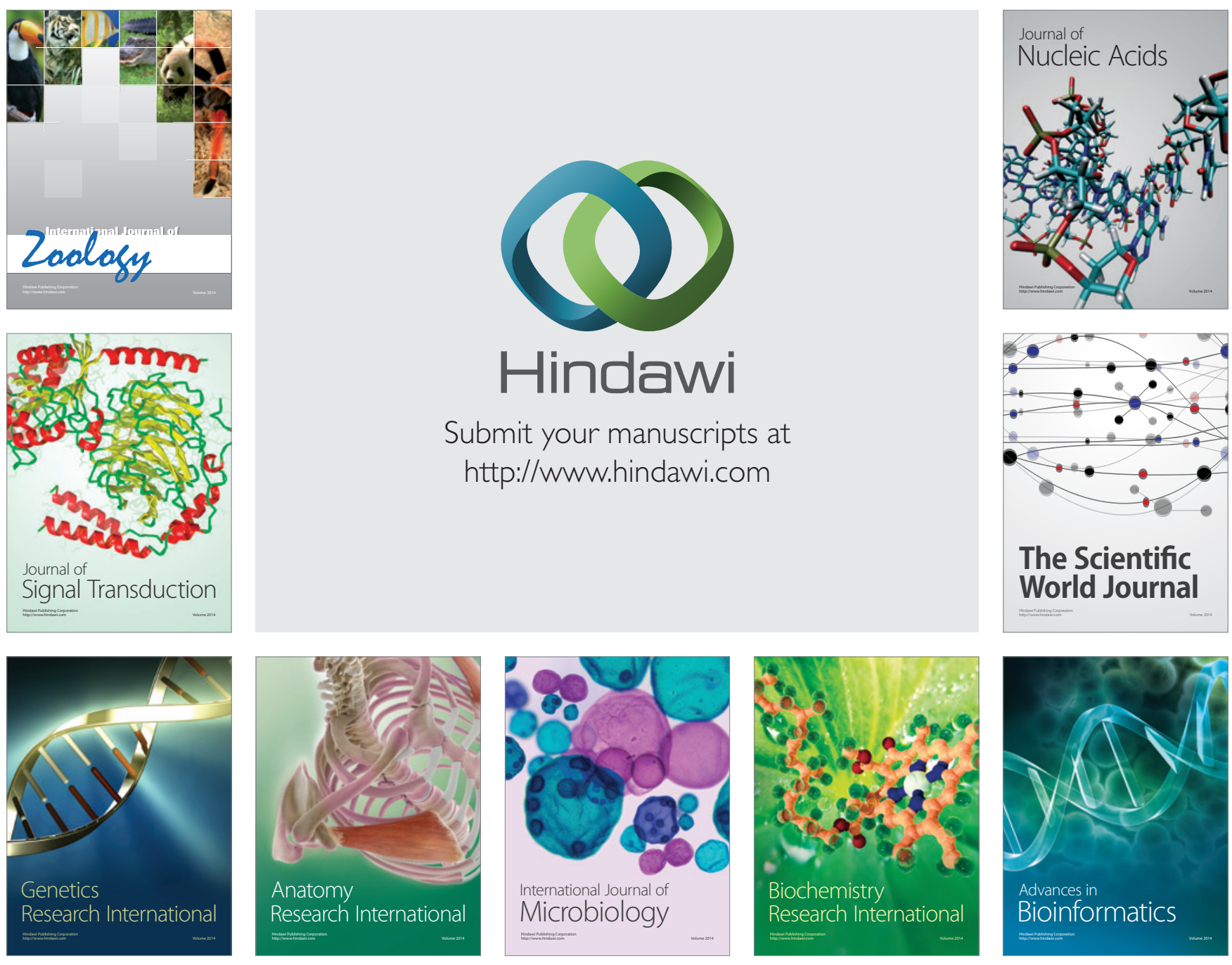

The Scientific World Journal
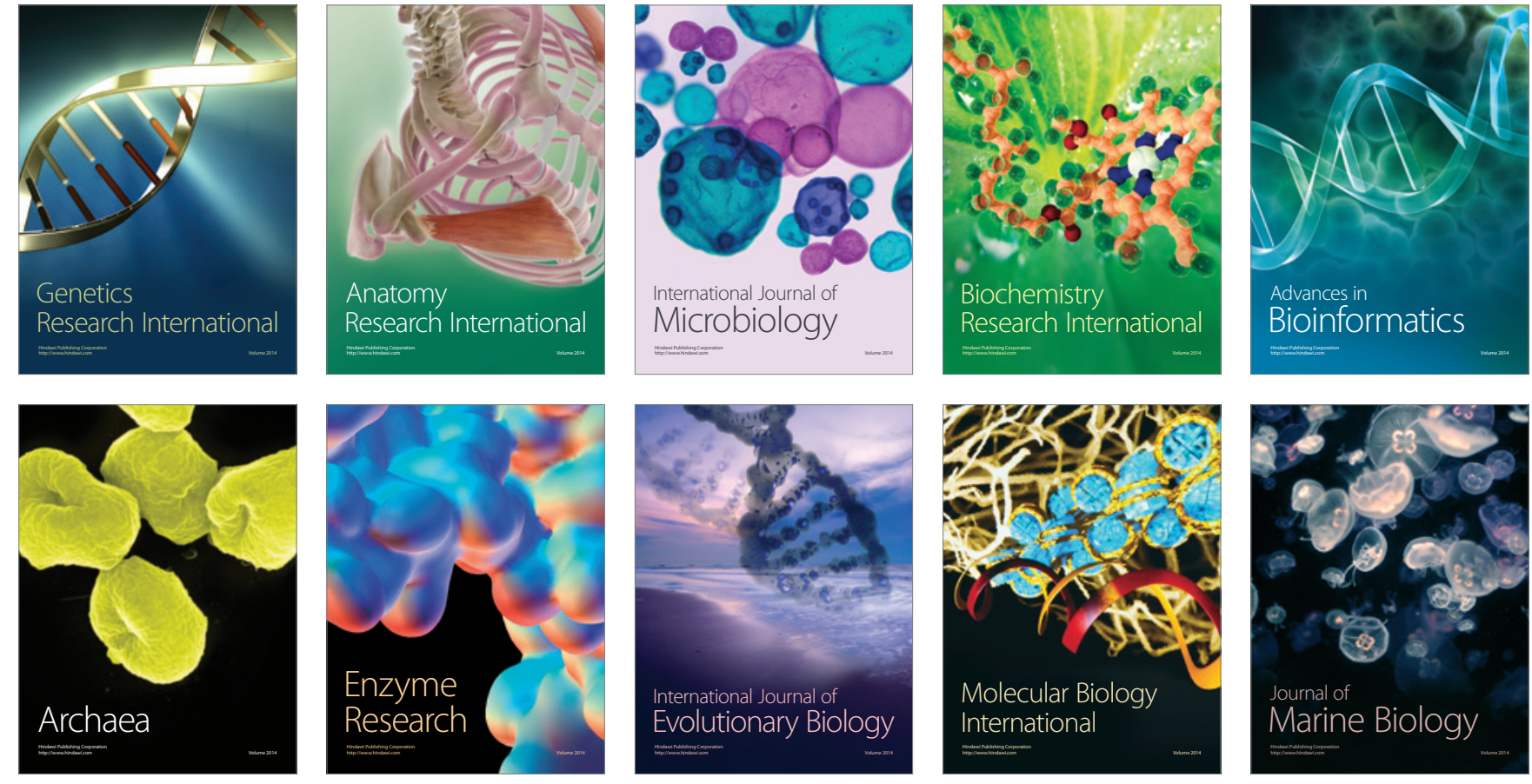